\title{
Overlapping Key Populations and HIV Transmission in Tijuana, Mexico: A Modelling Analysis of Epidemic Drivers
}

\author{
Hannah Fraser ${ }^{1} \cdot$ Annick Borquez ${ }^{2} \cdot$ Jack Stone ${ }^{1} \cdot$ Daniela Abramovitz $^{2} \cdot$ Kimberly C. Brouwer $^{2}$. \\ David Goodman-Meza ${ }^{3}$ Matthew Hickman ${ }^{1}$. Thomas L. Patterson ${ }^{2} \cdot$ Jay Silverman $^{2} \cdot$ Laramie Smith $^{2}$. \\ Steffanie A. Strathdee ${ }^{2} \cdot$ Natasha K. Martin $^{2,1}$. Peter Vickerman ${ }^{1}$
}

Accepted: 20 June 2021 / Published online: 3 July 2021

(c) The Author(s) 2021

\begin{abstract}
Tijuana, Mexico, has a concentrated HIV epidemic among overlapping key populations (KPs) including people who inject drugs (PWID), female sex workers (FSW), their male clients, and men who have sex with men (MSM). We developed a dynamic HIV transmission model among these KPs to determine the extent to which their unmet prevention and treatment needs is driving HIV transmission. Over 2020-2029 we estimated the proportion of new infections acquired in each KP, and the proportion due to their unprotected risk behaviours. We estimate that $43.7 \%$ and $55.3 \%$ of new infections are among MSM and PWID, respectively, with FSW and their clients making-up $<10 \%$ of new infections. Projections suggest $93.8 \%$ of new infections over 2020-2029 will be due to unprotected sex between MSM or unsafe injecting drug use. Prioritizing interventions addressing sexual and injecting risks among MSM and PWID are critical to controlling HIV in Tijuana.
\end{abstract}

Keywords Mathematical modelling $\cdot$ People who inject drugs $\cdot$ Female sex workers $\cdot$ Men who have sex with men $\cdot$ Mexico

\section{Resumen}

Tijuana, México, tiene una epidemia de VIH concentrada en poblaciones claves (PC) superpuestas que incluyen personas que se inyectan drogas (PID), trabajadoras sexuales (MTS), sus clientes hombres, y hombres que tienen sexo con hombres (HSH). Desarrollamos un modelo dinámico de transmisión de VIH en estas PC para determinar hasta dónde sus necesidades no atendidas de prevención y tratamiento dirigen la transmisión del VIH. Para 2020-2029 estimamos la proporción de nuevas infecciones adquiridas en cada PC, y la proporción atribuida a sus comportamientos de riesgo sin protección. Estimamos que $43.7 \%$ y $55.3 \%$ de nuevas infecciones se dan en HSH y PID, respectivamente, con MTS y clientes conformando $<10 \%$ de nuevas infecciones. Las proyecciones sugieren que 93.8\% de nuevas infecciones en 2020-2029 se deberán a sexo sin protección en HSH o uso inseguro de drogas inyectables. Dar prioridad a intervenciones que atienden los riesgos sexual y de inyección en HSH y PID es crítico para controlar el VIH en Tijuana.

Palabras claves Modelo matemáticopersonas que se inyectan drogas $\cdot$ Mujeres trabajadoras sexuales $\cdot$ Hombres que tienen sexo con hombres · México

Natasha K. Martin and Peter Vickerman are joint last authors.

Hannah Fraser

hannah.fraser@bristol.ac.uk

Peter Vickerman

peter.vickerman@bristol.ac.uk

1 Oakfield House, Population Health Sciences - Bristol Medical School, University of Bristol, Bristol BS8 2BN, UK

2 School of Medicine, University of California San Diego, San Diego, USA

3 David Geffen School of Medicine, University of California Los Angeles, Los Angeles, CA, USA

\section{Introduction}

HIV still causes significant global morbidity [1]. Marginalised populations including men who have sex with men (MSM), female sex workers (FSW) and people who inject drugs (PWID) experience the highest disease burden [1]. It is a global priority to quantify the contribution of these key populations (KPs) to on-going HIV transmission and identify interventions to reduce this risk [2-4].

Tijuana, Mexico, is situated on a major drug trafficking route to the US [5]. Sex work is tolerated by police within Tijuana's zona roja $[6,7]$, with this area also having a 
thriving drug market [8]. There is also considerable MSM living in Tijuana [9].

The coverage of interventions to reduce HIV transmission among KPs in Tijuana are low. For PWID, the availability of sterile injecting equipment has reduced since support from the Global Fund finished in 2013 [10]. Whilst antiretroviral therapy (ART) coverage is $~ 70 \%$ in the general population [11], coverage is much lower among KPs. Similarly, while HIV pre-exposure prophylaxsis (PrEP) effectively prevents HIV acquisition, uptake is low in Tijuana [12].

Mexico has a low adult HIV prevalence (0.54\% [9]), but higher prevalence among KPs [11]. In Tijuana, the estimated HIV prevalence in 2012/13 was 2.7\% in FSW [13], 17.3\% in MSM [14] and 3.5\% in PWID [15]. Data also suggests that over one-third of female PWID have recently sold sex [16], a fifth of FSW have ever injected drugs [6], and over one-third of male PWID have ever had sex with men [15], illustrating the overlapping transmission network within Tijuana $[17,18]$.

While these are useful insights, it is unclear how the unmet treatment and prevention needs of these KPs are contributing to HIV transmission, and therefore how interventions should be targeted. We use HIV transmission modelling to consider this question.

\section{Methods}

\section{Model Structure}

We developed a dynamic HIV transmission model incorporating sexual and injecting HIV transmission among KPs in Tijuana (Supplementary Figures S1\&S2).

The female population was stratified into three FSW and PWID groups, while the male population was stratified into seven PWID, MSM and male clients of FSW (denoted as clients) groups (Supplementary Figure S1). Individuals can start one risk behaviour and subsequently initiate another. PWID can cease injecting, FSW and clients can cease selling and buying sex, but MSM remain as MSM.

All individuals enter the model susceptible to HIV. Upon infection, individuals acquire acute HIV infection, before progressing to chronic infection, pre-AIDS, and AIDS [19, 20], whereupon they experience AIDS-related mortality. HIV-infected individuals can initiate (and cease) ART, which reduces disease progression and AIDS-related mortality [21-24]. All individuals experience non-HIV mortality, which is heightened in PWID [25].

HIV transmission occurs among KPs through: heterosexual vaginal and anal sex between men and women from all groups (Supplementary Figure S3); vaginal and anal commercial sex between FSW and clients; anal sex among MSM; and injecting drug use (IDU) among PWID. An individual's risk of HIV acquisition is related to the HIV prevalence of their sexual or injecting partners. Transmission risk differs for injecting and sexual behaviours [26-28], is elevated if their partners have acute or pre-AIDS infection [19], and is reduced if they are on ART [21-24]. Transmission risk is also related to the frequency and type of sex act for different partnerships, and consistency of condom use. We assume a proportion of heterosexual partnerships are with the general population, and have negligible risk due to their low HIV prevalence. All other partnerships occur between individuals within the modelled population, with random mixing among sub-groups (see Supplementary Materials). We do not model the use of HIV pre-exposure prophylaxis (PrEP) due to its low uptake in Tijuana [12].

\section{Model Parameterisation}

We parameterized our model to Tijuana using data from local studies (Supplementary Table I). Parameters are given in Table 1 and Supplementary Table II.

Using survey data, a PWID's injecting frequency was generally assumed to be 1,440 (IQR: 1080-1440) per year, but higher for MSM-PWID and lower for non-FSW PWID. Two-thirds $(67.9 \%, 95 \%$ CI:63.3-72.5\%) of PWID were assumed to share syringes in the last 6 months, although this was heightened among some sub-groups.

Consistency of condom use varies according to KP, partner type and over time, increasing linearly from 1987 [29, 30] up to our survey estimates, with uncertainty being incorporated in the time that this was achieved (up to 10 years earlier).

Based on survey data, nearly two-thirds of MSM were assumed to have main (2 per year, IQR:1-2) and casual male partners (12 per year, IQR:0-48). Commercial sex only occurs between FSW and their male clients, with FSWs having commercial sex every $2-3$ days and clients once a month.

ART was assumed to have started in 2003, with coverage being 2-18\% amongst PWID and FSW in 2012 [15, 31, 32] and 15-45\% amongst MSM and clients in 2017 (unpublished data). Further details of all model parameters are given in the Supplementary Materials.

Priors for the number of individuals in each overlapping group were estimated as follows. We firstly assumed 10,000 PWID [5], with 15.0\% (95\%CI:12.8-17.1\%) of PWID [5] being female. We then estimated the number of FSWs and their overlap with PWID using survey data on injecting behaviours among FSW and commercial sex behaviour among female PWID, estimating 1709 (1620-1826) FSW in 2020 with 477 (443-507) FSW-PWID (Supplementary Figure S4). The client population size was determined through balancing the reported frequency of commercial sex for FSW and clients, giving 8678 clients $(7565-10,867)$. The 
Table 1 Summary of key parameter ranges used for different population groups

\begin{tabular}{|c|c|c|c|c|}
\hline & Prior distribution & Distribution & p-value (if applicable) & Data information \\
\hline \multicolumn{5}{|l|}{ (i) Injecting drug use } \\
\hline \multicolumn{5}{|l|}{$\begin{array}{l}\text { Number of injections in the } \\
\text { past year among PWID }\end{array}$} \\
\hline $\begin{array}{l}\text { Female PWID-FSW; Male } \\
\text { PWID; Male PWID- } \\
\text { Clients }\end{array}$ & 1440 (IQR: 1080-1440) & Triangular & & ECIV \\
\hline PWID-MSM & RR: 1.3 (95\%CI: 1.0-1.7) & Log-normal & 0.0369 ( $\chi^{2}$ test $)$ & $\begin{array}{l}\text { ECIV; (RR compared to male } \\
\text { PWID) }\end{array}$ \\
\hline Female PWID non-FSW & RR: 0.9 (95\%CI: 0.8-1.0) & Log-normal & $0.0179\left(\chi^{2}\right.$ test $)$ & $\begin{array}{l}\text { ECIV; (RR compared to male } \\
\text { PWID) }\end{array}$ \\
\hline \multicolumn{5}{|l|}{$\begin{array}{l}\text { Proportion of PWID who } \\
\text { have ever shared syringes } \\
\text { in the past } 6 \text { months }\end{array}$} \\
\hline $\begin{array}{l}\text { Female PWID non-FSW; } \\
\text { Male PWID only }\end{array}$ & $67.9 \%(63.3-72.5 \%)$ & Truncated normal & & ECIV \\
\hline PWID-client & $\begin{array}{l}\text { OR: } 14.2 \text { (95\%CI: } 1.91- \\
104.9)\end{array}$ & Log-normal & $<0.0001$ ( $\chi^{2}$ test $)$ & $\begin{array}{l}\text { ECIV; (OR compared to male } \\
\text { PWID) }\end{array}$ \\
\hline PWID-MSM & OR: 3.0 (95\%CI: $1.0-10.29)$ & Log-normal & $0.0691\left(\chi^{2}\right.$ test $)$ & $\begin{array}{l}\text { ECIV; (OR compared to male } \\
\text { PWID) }\end{array}$ \\
\hline PWID-FSW & OR: 1.5 (95\%CI: 1.0-2.26) & Log-normal & 0.0471 ( $\chi^{2}$ test $)$ & $\begin{array}{l}\text { ECIV; (OR compared to male } \\
\text { PWID) }\end{array}$ \\
\hline $\begin{array}{l}\text { Proportion who shared at } \\
\text { last injection (if shared in } \\
\text { the past } 6 \text { months) - same } \\
\text { estimate used for all PWID } \\
\text { groups }\end{array}$ & $45.9 \%(38.7-53.2 \%)$ & Truncated normal & & ECIV \\
\hline \multicolumn{5}{|l|}{ (ii) Men who have sex with men } \\
\hline $\begin{array}{l}\text { Proportion of MSM with } \\
\text { at least one main male } \\
\text { partner in last year }\end{array}$ & $62.3 \%$ (95\%CI: $55.4-69.2 \%)$ & Truncated normal & & Proyecto $\mathrm{H}$ \\
\hline $\begin{array}{l}\text { Number of main male part- } \\
\text { ners per year (among those } \\
\text { that have them in last year) }\end{array}$ & 2 (IQR: 1-2) & Triangular & & Proyecto $\mathrm{H}$ \\
\hline $\begin{array}{l}\text { Frequency of sex acts in } \\
\text { past year with each main } \\
\text { partner }\end{array}$ & 25.2 (IQR: 10.2-78) & Triangular & & Proyecto $\mathrm{H}$ \\
\hline $\begin{array}{l}\text { Consistency of condom use } \\
\text { for main partners of MSM }\end{array}$ & $60.8 \%(52.3-69.2 \%)$ & Truncated normal & & Proyecto $\mathrm{H}$ \\
\hline $\begin{array}{l}\text { Proportion of MSM with } \\
\text { at least one casual male } \\
\text { partner in last year }\end{array}$ & $60.3 \%(53.2-67.2 \%)$ & Truncated normal & & Proyecto $\mathrm{H}$ \\
\hline $\begin{array}{l}\text { Number of casual male part- } \\
\text { ners per year (among those } \\
\text { that have them in last year) }\end{array}$ & 6 (IQR: 0-24) & Triangular & & Proyecto $\mathrm{H}$ \\
\hline $\begin{array}{l}\text { Frequency of sex acts in } \\
\text { past year with each casual } \\
\text { partner }\end{array}$ & 1.1 (IQR: 1-2) & Triangular & & Proyecto $\mathrm{H}$ \\
\hline $\begin{array}{l}\text { Consistency of condom use } \\
\text { for casual partners of MSM }\end{array}$ & $77.9 \%(71.1-84.8 \%)$ & Truncated normal & & Proyecto $\mathrm{H}$ \\
\hline \multicolumn{5}{|c|}{ (iii) Commercial sex - Female sex workers and their clients } \\
\hline \multicolumn{5}{|l|}{$\begin{array}{l}\text { Number of commercial sex } \\
\text { contacts per year }\end{array}$} \\
\hline FSW-PWID & 180 (IQR: 72-360) & Triangular & & MAPA and MMS \\
\hline FSW non-PWID & 120 (IQR: 60-240) & Triangular & & MAPA and MMS \\
\hline Clients & 12 (IQR: 6-24) & Triangular & & Sexo Seguro \\
\hline
\end{tabular}


Table 1 (continued)

\begin{tabular}{|c|c|c|c|c|}
\hline & Prior distribution & Distribution & p-value (if applicable) & Data information \\
\hline \multicolumn{5}{|l|}{$\begin{array}{l}\text { Consistency of condom use } \\
\text { in last commercial sex act } \\
\text { among }\end{array}$} \\
\hline $\begin{array}{l}\text { Non-PWID FSW reported } \\
\text { with clients }\end{array}$ & $85.5 \%(82.0-89.0 \%)$ & Normal & & MAPA \\
\hline $\begin{array}{l}\text { PWID FSW reported with } \\
\text { clients }\end{array}$ & RR: 0.8 (95\%CI: 0.6-0.9) & Truncated log-normal & $<0.001$ ( $\chi^{2}$ test $)$ & $\begin{array}{l}\text { MAPA; (RR compared to non- } \\
\text { PWID FSW) }\end{array}$ \\
\hline $\begin{array}{l}\text { Clients reported with FSW } \\
\text { (vaginal sex) }\end{array}$ & $54.8 \%(48.3-61.3 \%)$ & Normal & & Sexo Seguro \\
\hline $\begin{array}{l}\text { Clients reported with FSW } \\
\text { (anal sex) }\end{array}$ & $45.8 \%(32.7-58.9 \%)$ & Normal & & Sexo Seguro \\
\hline \multicolumn{5}{|l|}{$\begin{array}{l}\text { Proportion of commercial } \\
\text { sex acts that are vaginal }\end{array}$} \\
\hline $\begin{array}{l}\text { FSW with client non- } \\
\text { PWID }\end{array}$ & $84.5 \%(81.7-87.4 \%)$ & Truncated normal & & Sexo Seguro \\
\hline FSW with client PWID & RR 0.9 (95\%CI: $0.8-1)$ & Log normal & $0.0325\left(\chi^{2}\right.$ test $)$ & Sexo Seguro \\
\hline \multicolumn{5}{|c|}{ (iv) Heterosexual main partnerships } \\
\hline \multicolumn{5}{|c|}{ Percentage of each key population with a main partner-included in Supplementary materials as different for each group } \\
\hline \multicolumn{5}{|l|}{$\begin{array}{r}\text { Frequency of vaginal sex } \\
\text { acts in past year among }\end{array}$} \\
\hline $\begin{array}{l}\text { Female PWID non-FSW } \\
\text { with males }\end{array}$ & 48 (IQR: 5-48) & Triangular & & ECIV \\
\hline $\begin{array}{l}\text { FSW (PWID and non- } \\
\text { PWID) with males }\end{array}$ & 48 (IQR: 20-48) & Triangular & & ECIV \\
\hline Male PWID with females & 48 (IQR: 20-48) & Triangular & & ECIV \\
\hline Male Clients with females & 60 (IQR: 24-120) & Triangular & & Hombre Seguro \\
\hline MSM with females & 24 (IQR: 6-60) & Triangular & & Proyecto $\mathrm{H}$ \\
\hline \multicolumn{5}{|l|}{$\begin{array}{l}\text { Frequency of anal sex acts in } \\
\text { past year among }\end{array}$} \\
\hline All females with males & 0 (IQR: 0-5) & Triangular & & ECIV \\
\hline $\begin{array}{l}\text { Males (non-MSM) with } \\
\text { females }\end{array}$ & $0-6$ & Uniform & & ECIV/Hombre Seguro \\
\hline MSM with females & 6 (IQR: 0.96-19.5) & Triangular & & Proyecto $\mathrm{H}$ \\
\hline $\begin{array}{l}\text { Consistency of condom use } \\
\text { in last sex act for main } \\
\text { partnerships }\end{array}$ & & & & $\begin{array}{l}\text { Range over max and min for } \\
\text { different surveys }\end{array}$ \\
\hline Vaginal sex & $8.7-28.3 \%$ & Uniform & & \\
\hline Anal sex & $4-32.3 \%$ & Uniform & & \\
\hline \multicolumn{5}{|c|}{ (iv) Heterosexual casual partnerships } \\
\hline \multicolumn{5}{|c|}{ Percentage of each key population with at least one casual partner - included in Supplementary materials as different for each group } \\
\hline \multicolumn{5}{|c|}{$\begin{array}{l}\text { Number of casual partners in } \\
\text { past year }\end{array}$} \\
\hline $\begin{array}{l}\text { Female PWID non-FSW } \\
\text { with males }\end{array}$ & 2 (IQR: 2-4) & Triangular & & ECIV \\
\hline FSW PWID with males & 6 (IQR: 4-20) & Triangular & & ECIV \\
\hline Male PWID with females & 4 (IQR: 4-6) & Triangular & & ECIV \\
\hline MSM with females & 12 (IQR: 6-24) & Triangular & & Proyecto $\mathrm{H}$ \\
\hline Clients with females & 9 (IQR: 6-12) & Triangular & & Sexo Seguro \\
\hline
\end{tabular}


Table 1 (continued)

\begin{tabular}{|c|c|c|c|c|}
\hline & Prior distribution & Distribution & p-value (if applicable) & Data information \\
\hline \multicolumn{5}{|l|}{$\begin{array}{r}\text { Frequency of vaginal sex } \\
\text { acts in past year among }\end{array}$} \\
\hline $\begin{array}{l}\text { Female PWID non-FSW } \\
\text { with males }\end{array}$ & 0.75 (IQR: 0-2.5) & Triangular & & ECIV \\
\hline FSW PWID with males & 1.25 (IQR: 0.007-8) & Triangular & & ECIV \\
\hline Male PWID with females & 0.833 (IQR: 0-6) & Triangular & & ECIV \\
\hline MSM with females & 1 (IQR: 1-1.5) & Triangular & & Proyecto $\mathrm{H}$ \\
\hline Clients with females & 1.3 (IQR: 1-3) & Triangular & & Sexo Seguro \\
\hline \multicolumn{5}{|l|}{$\begin{array}{l}\text { Frequency of anal sex acts in } \\
\text { past year among }\end{array}$} \\
\hline All females with all males & 0 (IQR: 0-0.25) & Triangular & & ECIV \\
\hline All males with all females & $0-1$ & Uniform & & Range over male surveys \\
\hline $\begin{array}{l}\text { Consistency of condom use } \\
\text { in last sex act for casual } \\
\text { partnerships }\end{array}$ & & & & Take range over all surveys \\
\hline Vaginal sex & $23.3-60.3 \%$ & Uniform & & \\
\hline Anal sex & $5.2-88.7 \%$ & Uniform & & \\
\hline
\end{tabular}

This is included to give a summary with full details of the data used to calibrate the model and prior parameter ranges in the supplementary materials Note that for normal and log-normal distributions the mean and 95\% confidence intervals (CI) are given; for triangular distributions the median and interquartile range were used to create the distribution (unless otherwise stated); for uniform distributions a range was taken over the data

${ }^{a}$ To determine frequency of anal sex acts in the past year the rates between males and females are both sampled and then the average of the two is used in the model

${ }^{\mathrm{b}}$ Condom use estimates for commercial sex were averaged across reported use by FSW and clients

number of MSM was estimated through different studies, 5276 (4501-6413) (Supplementary Table III).

\section{Model Calibration}

Using an approximate Bayesian computation sequential Monte Carlo (ABC SMC) scheme, accounting for uncertainty in the calibration data and parameters [33], the model was calibrated to our population size estimates; HIV prevalence estimates among all PWID (2005/2007/2012), FSW (2005/2011/2013) and MSM (2012); and ART coverage estimates for PWID (2012), FSW (2012), MSM (2017) and clients (2017) (Supplementary Tables I\&II). This scheme starts with 5,000 parameter sets randomly sampled from their prior distributions, which are iteratively perturbed to improve the goodness-of-fit until we achieve our desired criteria, so producing a set of 5,000 baseline model fits (see Supplementary Materials).

\section{Model Validation}

To assess whether the model replicated observed epidemiological trends that it was not calibrated to, the baseline model fits were compared against six HIV incidence estimates among PWID, FSW and clients, and 16 HIV prevalence estimates among PWID and FSW by PWID status.
We estimated the average proportion of the $95 \%$ confidence intervals $(95 \% \mathrm{CI})$ for these 22 data estimates that the baseline model fits passed through.

\section{Impact of Existing Interventions}

The model was used to estimate the impact of historical increases in condom use and ART coverage. Compared to counterfactual scenarios where the baseline model fits were run with either no increase in condom use from 1987 or no ART coverage from 2003, we estimated the percentage of infections prevented by either of these intervention until 2020.

\section{Contribution of Key Populations and Risk Behaviours to new HIV Infections over 2020-2029}

For 10-years over 2020-2029, we used the baseline model fits to assess the contribution of each KP and their risk behaviours to new/incident HIV infections occurring among KPs over 2020-2029. This is useful for estimating the best that can be achieved from targeting interventions to different KPs or risk behaviours. 


\section{Contribution of Different Key Populations}

We estimated the proportion of all new infections occurring among each KP over 2020-2029. We then estimated the proportion of new infections that are prevented across all KPs if for each KP in turn, both the risks of becoming infected and infecting others were removed over 2020-2029; equivalent to a perfect intervention making that KP not infectious or susceptible to infection. Although no perfect interventions exist, this impact is likely to be nearly realised with full scale-up of both prevention and treatment interventions such that nearly all transmission is removed.

\section{Contribution of Different Risk Behaviours}

For each risk behaviour (commercial sex, sex between men, non-commercial heterosexual sex and unsafe IDU), we estimated the proportion of new HIV infections prevented over 2020-2029 if the risk of HIV transmission for each risk behaviour was removed over that time period; equivalent to a perfect intervention making that risk behaviour fully protected. We repeated this for each KP by estimating the proportion of new infections prevented in that KP if their different risk behaviours were fully protected over 2020-2029.

\section{Sensitivity Analysis}

We determined the importance of uncertainty in individual parameters to the overall variability in our estimates for the contribution of different risk behaviours to incident HIV infections over 2020-2029. We performed a linear regression analysis of covariance [34] across our baseline model fits.

Due to uncertainty in the current ART coverage in MSM and clients, we determined how the contribution of different risk behaviours to incident HIV infections would change if the ART coverage in MSM and clients were at national levels for men (70\% coverage in 2018). Similarly, because circumstantial evidence suggests that MSM who inject drugs mainly do so with other MSM, we estimated the effect of assuming that MSM-PWID only mix with each other when injecting. We also investigated if the contribution of risk behaviours to incident HIV infections differed for 2010-2019 compared to 2020-2029. Lastly, we investigated the effect of calibrating the model to additional HIV prevalence data among female PWID and FSW-PWID to determine whether this would effect our projections.

\section{Results}

\section{Model Fit to Data}

The baseline model fits reproduced the calibration data (Fig. 1), with HIV prevalence peaking around 2003 among FSW, MSM and clients, but being more uncertain among PWID. The decrease in prevalence post-2003 is due to HIVrelated mortality, mainly among MSM, causing a decrease in HIV prevalence in all sub-groups due to their interactions. In 2020, HIV prevalence amongst PWID, FSW, MSM and clients is projected to be $4.4 \%$ (95\% credible interval (95\% CrI):2.1-12.1\%), $4.8 \%$ (95\% CrI:3.4-6.7\%), 20.6\% (95\% CrI: $12.7-26.7 \%)$ and $1.4 \%$ (95\% CrI:1.0-1.7\%), respectively.

The model validated well against available HIV incidence and prevalence data that it was not calibrated to (Supplementary Figures S6\&S7). On average, the 5,000 baseline model fits fell within $85.9 \%$ of the $95 \%$ CIs for the 6 incidence validation points and $63.9 \%$ of the $95 \%$ CIs for the 16 prevalence validation points.

\section{Impact of Existing Interventions}

Historic increases in condom use during commercial sex over 1987-2020 have averted 476 (95\%CrI:333-753) or 7.8\% (95\% CrI:5.9-11.3\%) of new infections occurring among KPs over that period. Conversely, 5087 (95\%CrI:4033-6453) or $47.4 \%$ (95\% CrI:38.0-58.0\%) of new infections occurring among KPs were prevented through increases in condom use among MSM. Lastly, existing ART coverage has prevented 656 (95\%CrI:507-862) or 18.5\% (95\%CrI:12.6-23.0\%) of infections occurring among KPs since 2003.

\section{Contribution of Different Key Populations to HIV Transmission}

Across all KPs, the model projects 1608 (95\% CrI:909-3821) new HIV infections over 2020-2029, with most occurring among MSM and PWID and being due to their risk behaviours (Fig. 2). Whilst MSM only make up $22.8 \%$ (95\% CrI:20.1-26.0\%) of all KP in 2020, $43.7 \%$ (95\%CrI: $15.9-79.7 \%)$ of new infections occurred among MSM over 2020-2029 and 50.0\% (95\%CrI:17.9-90.1\%) of all new HIV infections occurring among KP will be prevented if all MSM risk behaviours are fully protected. Similarly, PWID comprise $41.1 \%$ (95\%CrI:36.8-44.0\%) of all $\mathrm{KP}$ in 2020, with $55.3 \%$ (95\% CrI: $19.7-82.5 \%$ ) of new infections occurring among PWID over 2020-2029 and 65.2\% (95\%CrI:36.0-87.7\%) of all new HIV infections occurring among KP being prevented if all PWID risk behaviours are fully protected (sexual and injecting risk behaviours). 
(a)

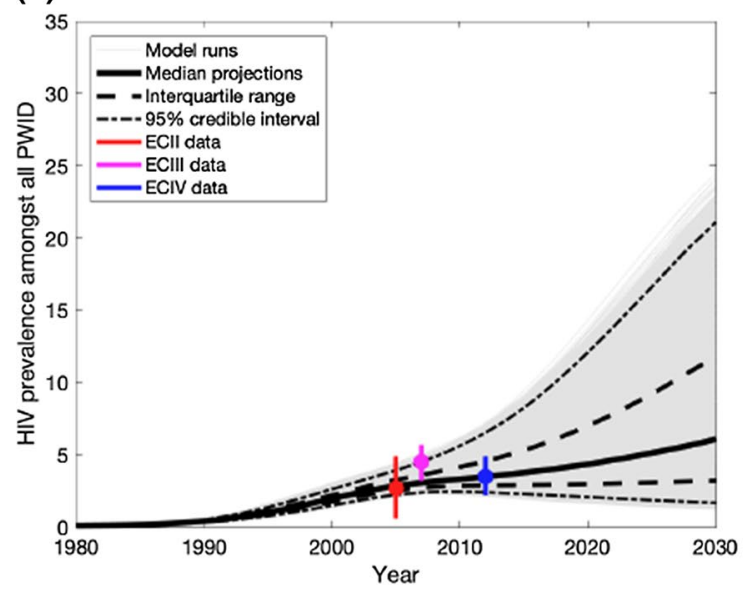

(c)

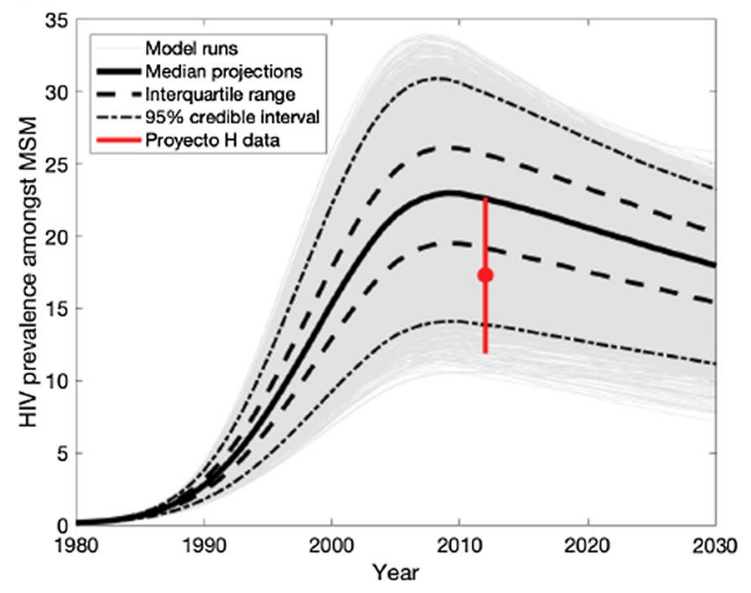

Fig. 1 HIV prevalence projections and available data estimates for a PWID; b FSW; c MSM and d clients in Tijuana, Mexico. The model was calibrated to HIV prevalence data amongst PWID, FSW and MSM (denoted by circles [mean] and vertical lines [95\% confidence intervals]), as well as ART coverage data for all four key populations. Pale grey lines show the model projections for each of the runs,

In contrast, FSW and their clients contribute much less to transmission, with $11.2 \%$ (95\% CrI:6.5-18.1\%) and $16.8 \%$ (95\%CrI:6.8-32.0\%) of new HIV infections occurring among KP being prevented if all risk behaviours of FSWs or clients are fully protected, respectively.

\section{Contribution of Different Risk Behaviours to all HIV Transmission}

Among all KPs, unprotected sex between men and unsafe IDU accounts for most new infections, with $45.8 \%$ (95\%CrI: $16.4-83.6 \%$ ) and $48.4 \%$ (95\%CrI:6.0-80.6\%) of new HIV infections occurring among KPs being prevented over 2020-2029, respectively, if these risk behaviours are fully protected (Fig. 3). However, the contribution of these (b)

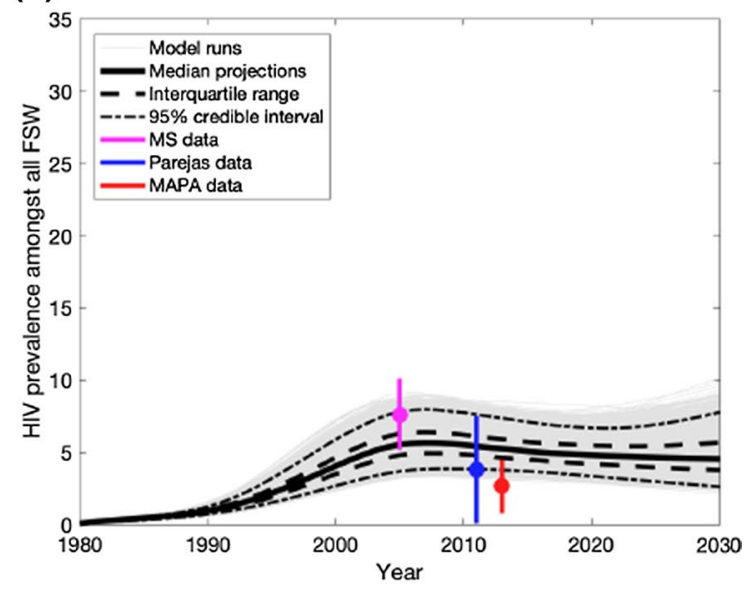

(d)

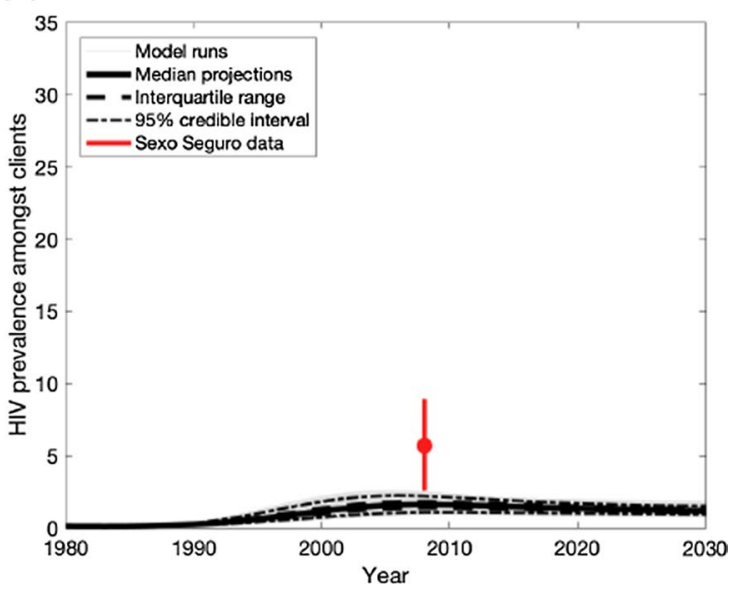

solid black lines show the median of the model runs, dashed black lines show the interquartile range of model runs, and dot-dashed lines show the $95 \%$ credibility intervals. Note survey acronyms used in figures: ECII - El Cuete II; ECIII - El Cuete III; EC IV - El Cuete IV; MS - Mujer Segura; MAPA - Salud de MAPA

risk behaviours are uncertain and inversely related to each other (Supplementary Figure S8), with their overall contribution being high (93.8\%; 95\% CrI:88.2-97.1\%). In contrast, unprotected commercial sex and heterosexual main and casual sex both contribute less than $10 \%$ of new HIV infections occurring among KPs over 2020-2029.

\section{Contribution of Different Risk Behaviours to HIV Transmission for each Key Population}

For MSM, nearly all (99.7\%; 95\%CrI:98.8-99.9\%) new infections are averted over 2020-2029 if sex between men is fully protected (Fig. 4). Similarly, among PWID, most (86.0\%, 95\%CrI:30.0-96.2\%) new infections are averted when their injecting risk behaviours are protected, 
Fig. 2 Relative size of each key population, proportion of new infections that occur in each key population and contribution of each key population to HIV transmission over 2020-2029 in Tijuana, Mexico. Blue boxes denote the size of each key population group as a percentage of the total key population size. Orange boxes denote the percentage of new infections occurring within each key population over 2020-2029. Yellow boxes denote the proportion of new HIV infections occurring among KP that will be prevented if all risk behaviours of each key population are fully protected over 2020-2029.

Boxes in the figure show the 25th, 50th and 75th percentiles and the whiskers indicate the 2.5 th and 97.5 th percentiles

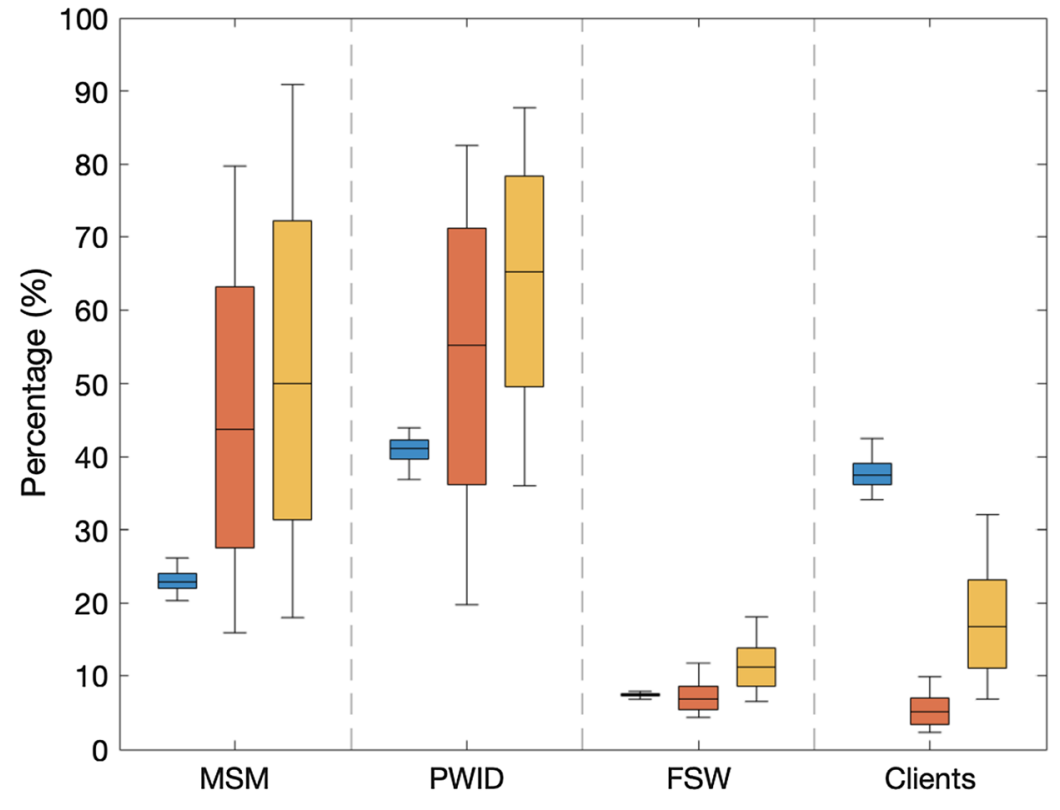

Percentage of total KP

Percentage of HIV infections acquired in each KP over 2020-2029

Percentage of HIV infections which are contributed due to each KP over 2020-2029

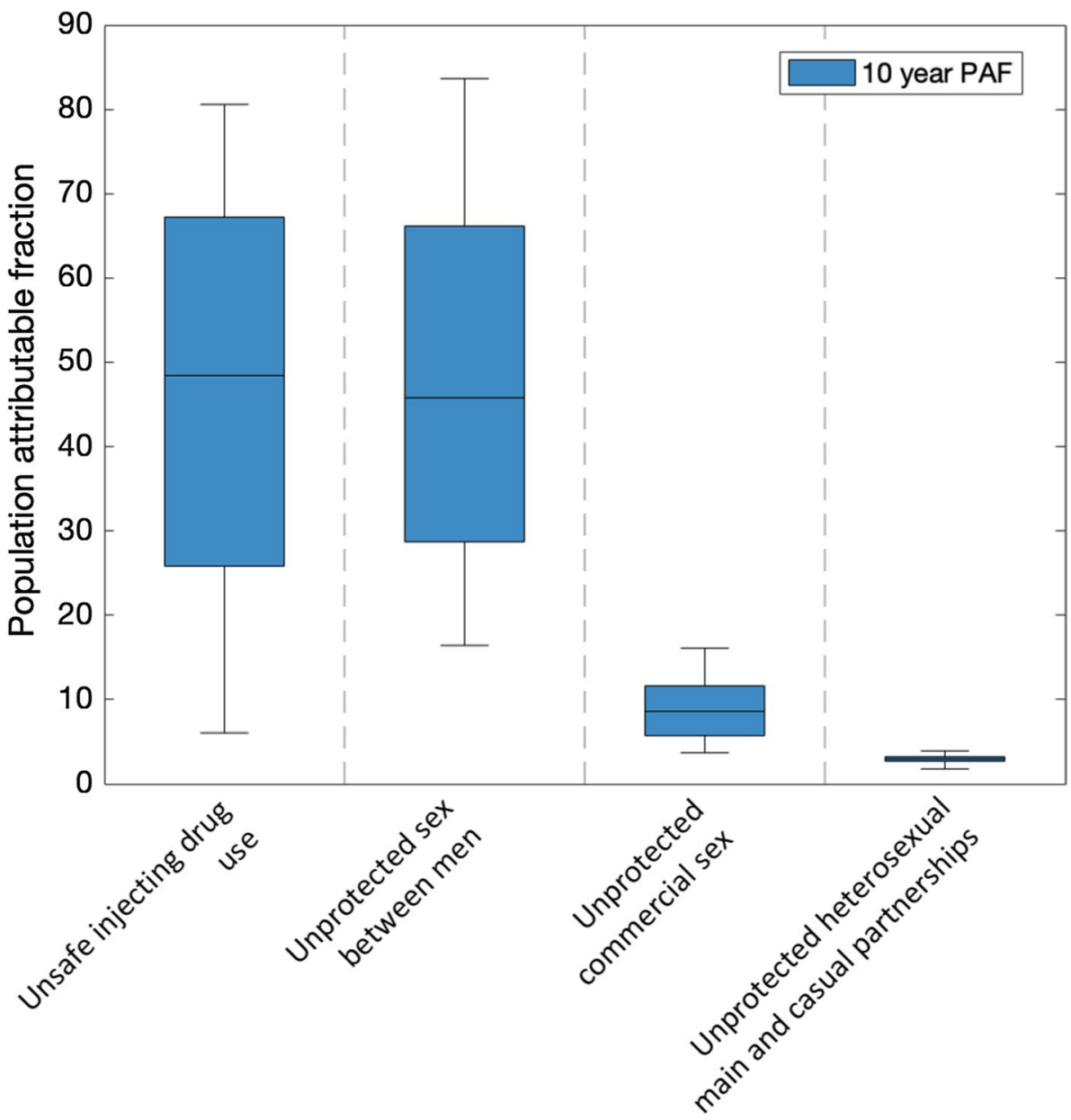

Fig. 3 The percentage of new HIV infections occurring among KP that will be prevented if different risk behaviours are fully protected in Tijuana over 2020-2029. Boxes show the 25th, 50th and 75th percentiles and the whiskers indicating the 2.5th-97.5th percentiles over the 5000 baseline model fits. The different scenarios are fully protecting either injecting HIV transmission risk, sex between men, commercial sex; heterosexual sex within main and casual partnerships 
Fig. 4 Percentage of new HIV infections occurring in each $\mathrm{KP}$ that will be prevented if different risk behaviours are fully protected over 2020-2029 in Tijuana. Boxes show the 25th, 50th and 75th percentiles and the whiskers indicating the 2.5th-97.5th percentiles

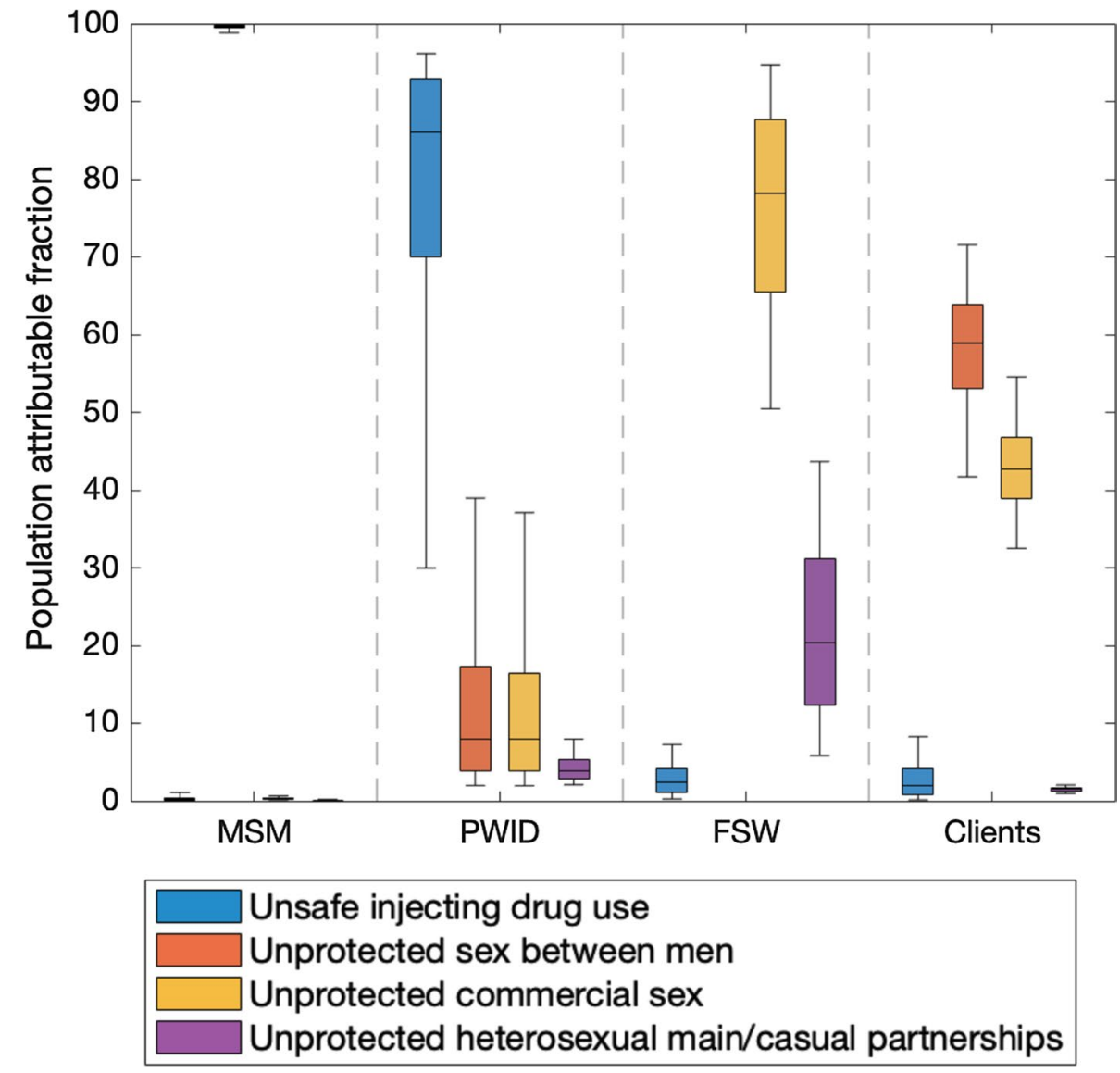

although some are also averted $(\sim 10 \%)$ from protecting their sexual risk behaviours. Among FSWs and their clients, most (62.4\%; 95\% CrI: 49.6-71.0\%) new HIV infections over 2020-2029 are averted if commercial sex is fully protected. Much of this is due to commercial anal sex, with $39.7 \%$ (95\% CrI: 26.9-39.7\%) of new infections being prevented if this behaviour is protected. Only a small percentage of infections are averted among FSW and their clients if their injecting risks are protected (2.8\%, 95\% CrI:0.3-9.4\%), while among clients, 58.9\% (95\% CrI:41.7-71.5\%) of new infections are averted if their sex with men is fully protected.

\section{Sensitivity Analysis}

Our ANCOVA analyses indicate that uncertainty in the HIV transmission probability for IDU contributes most to variability in the contribution of unprotected sex between men (95.9\%), unsafe IDU (96.4\%) and unprotected commercial sex $(91.9 \%)$ to new HIV infections occurring among KPs over 2020-2029. This variation results in the inverse relationship seen between the contribution of unprotected sex between men and unsafe IDU to new HIV infections (Supplementary Figure S8).

When the modelled HIV prevalence estimates (2020) for PWID, FSW and MSM are included in the ANCOVA, we find that uncertainty in the HIV prevalence of PWID contributes most to the variability in the contribution of unsafe injecting (88.0\%), unprotected sex between men (86.2\%) and unprotected commercial sex (74.9\%) to new HIV infections occurring among KPs. This mirrors what is seen when transmission probabilities are included in the ANCOVA analysis.

If we assume MSM only inject with other MSM (not other PWID), then the contributions of different risk behaviours to new HIV infections are very similar to our baseline findings (Supplementary Figure S9), similar also to what we find if ART coverage is increased among MSM and clients to national levels (70\% in 2018).

We also obtain similar results when we consider the contribution of different risk behaviours to new HIV infections over 2010-2019 instead of 2020-2029 (Supplementary Figure S10), with unprotected sex between men and unsafe IDU still accounting for most new infections occurring among KPs, but with unprotected sex between men now being the greater of 
the two. This also occurs when we calibrate the model to additional prevalence estimates, with unprotected sex between men again accounting for more new infections than unsafe injecting (Supplementary Figure S11).

\section{Discussion}

The overlap of Key populations (KPs) in Tijuana mean multiple HIV transmission routes exist, thereby complicating prevention efforts. We found that over half of on-going HIV transmission occurring among KPs in Tijuana could be prevented if improvements in interventions resulted in sex between men being fully protected, while two-thirds could be prevented if injecting drug use (IDU) was fully protected, indicating that interventions targeting these risk behaviours should be high priority in Tijuana.

Over four-fifths of infections among PWID are associated with unsafe IDU, likely due to minimal harm reduction interventions in Tijuana. This underscores the need to scale-up access to sterile injection equipment, which has become less available since 2013 [10]. Expansion of opioid agonist therapy (OAT), which can reduce the risk of HIV and HCV transmission, and fatal overdose [35, 36], is also needed. Modelling suggests that HIV infections among PWID could also be reduced if Mexico's policy towards decriminalizing drugs involved linking PWID to OAT instead of incarceration [37]. Importantly, HIV transmission among PWID is also associated with commercial sex and sex between men, indicating that comprehensive interventions addressing sexual risks are also needed.

Among FSW and clients, approximately three-quarters of transmission is due to unprotected commercial sex; therefore addressing this risk remains a high priority. Since sex work is quasi-legal in Tijuana, bars, motels and brothels should provide free access to condoms and promote other prevention approaches such as self-testing for HIV. These approaches should be extended to public sex venues, often frequented by MSM, because they are associated with condomless sex in Tijuana [38]. Previous studies have found that a brief intervention based on motivational interviewing among FSW, including those who injected drugs, is cost-effective in reducing the incidence of HIV and syringe-sharing [39, 40]. Efforts must also focus on structural factors that impede access to HIV prevention and treatment among PWID and sex workers, such as police harassment and abuse [16, 41, 42], with further modelling being needed to project the likely impact of different structural interventions for programme planning.

Despite large gaps in current prevention programming, our findings suggest that existing interventions have had impact. For instance, condom use amongst MSM has prevented nearly half of all HIV infections among KPs in Tijuana since its introduction. In contrast, due to low coverage, ART has only prevented $18.5 \%$ of infections since its initiation in 2003. Many challenges hamper access and retention in HIV care among KPs [43, 44] in Tijuana, including the low accessibility of the public HIV clinic [43]. Interventions to scale-up ART are needed to achieve greater coverage and impact, which could include clinics offering integrated services in Tijuana's zona roja accompanied by telemedicine, mobile clinics or peernavigators to promote engagement in HIV care and ART adherence. A recent modelling analysis [45] found that integrating ART and scaling up OAT in Tijuana could provide synergistic benefits through OAT enhancing ART uptake and retention, preventing HIV infections and overdose deaths, whereas the city's reliance on compulsory abstinence programmes could cause harm [45]. PrEP is highly effective among MSM in high-income countries [46], and can be highly effective among males and females in LMICs [47-49]. New longer acting PrEP options also show promise [50]. However, a recent study in Tijuana found that of those MSM aware of PrEP, only 4.8\% used PrEP [12]. Studies among MSM and FSW in Tijuana have indicated willingness to use PrEP, however perceived barriers to entry including costs and limited access need to be addressed [12, 51, 52].

\section{Strengths and Limitations}

The main strength of our analysis is the wealth of behavioural and epidemiological data from Tijuana used to parameterise and calibrate our model, which captures HIV transmission from overlapping risk behaviours among KPs.

Limitations include the difficulty in estimating the sizes of marginalised populations [53, 54]. Indeed, whilst population size estimates for PWID (6400-10,000) [55], FSW (4850-9000[55]) and MSM (12,227-20,378[9]) exist for Tijuana, these are old and were not based on reliable methods. Therefore, we estimated the population sizes of each KP by using survey data on the overlap of risk groups. This resulted in lower estimates for the number of FSW (1709, 95\% CrI:1620-1826) and MSM (5276, 95\% CrI:4501-6413). Although the overall number of KPs could be greater, their relative sizes will still need to remain consistent with each other as suggested by survey data. This means that the relative contribution of different risk behaviours should remain robust even if the estimated number of infections are rescaled for different KP sizes.

Secondly, although the model fit well to available HIV prevalence and ART coverage data, and was validated against 22 other prevalence and incidence data points, it was not able to fit all available data. Specifically, the projected HIV prevalence among clients was less than observed in surveys [18], meaning we may have underestimated the 
contribution of clients to HIV transmission. However, the survey used to estimate the HIV prevalence among clients is thought to have captured higher risk clients with higher HIV prevalence because many reported unprotected commercial sex and IDU [18]. Additionally, there was only one HIV prevalence estimate and no incidence data for MSM. Further studies are needed to better calibrate the MSM aspect of the model to confirm our findings that MSM contribute substantially to HIV transmission in Tijuana.

Thirdly, few estimates of ART coverage exist among KPs, with these being based on self-report. Reassuringly, sensitivity analyses suggest our results were not affected by this uncertainty.

\section{Comparison with Existing Literature}

A wealth of HIV modelling among KPs exists for other settings. While other models [56-59] have investigated HIV dynamics among multiple KPs, none have incorporated overlapping risk behaviours as we have. Other models have also incorporated heterogeneity in risk, but have focussed on fewer KPs [60-63] or just sexual HIV transmission [64-66]. Some models have estimated how unprotected risk behaviours of different KPs [67, 68] affect HIV transmission, highlighting the interventions required to reduce transmission risk, but have generally not considered how the overlapping dynamics of KPs may impact this. In settings like Tijuana, where multiple risk behaviours are highly prevalent, more granular models are needed to provide detailed insights. To date, HIV transmission models for Tijuana have focused on the cost-effectiveness of scaling-up interventions among particular KPs [40, 69] or modelling drug law reform among PWID [37, 41]. This study presents the first dynamic HIV transmission model among all main KPs in Tijuana.

\section{Conclusions}

Settings with overlapping KPs and multiple HIV risk behaviours will require multi-layered combined approaches to provide effective and efficient HIV prevention and treatment efforts. Our modelling indicates that prioritizing interventions to address sexual risk behaviours among MSM, and both sexual and injecting risks among PWID is critical to controlling the HIV epidemic in Tijuana. While some interventions need to be targeted at specific KPs, others are important for all KPs. For example, the coverage of harm reduction interventions is currently very low, and should be prioritised among PWID, while PrEP, which reduces HIV acquisition risk, should be introduced in all groups. In contrast, low ART coverage levels among all KPs highlight the urgent need for targeted scale-up to reduce mortality and prevent onwards HIV transmission among these groups. Our results suggest that reducing HIV acquisition (as PrEP does) and preventing onwards transmission (as ART does) could have a large impact on the number of infections occurring over the next 10 years, indicating the importance of scalingup interventions. To aid the prioritisation of this improvement in HIV programming, cost-effectiveness analyses are needed to identify the most efficient strategies to reduce HIV incidence in Tijuana.

Supplementary Information The online version contains supplementary material available at https://doi.org/10.1007/s10461-021-03361-2.

Authors contributions PV, NM and SAS conceptualized the study. HF developed the model and performed model analyses and reviewed literature for any additional data. PV and NM supervised the project. SAS, TP, KCB, DGM and LS provided data sets. DA and HF undertook data analysis for model parameterisation. HF and PV wrote the first draft of the manuscript. All authors contributed to data interpretation, writing the manuscript and approved the final version.

Funding This study was funded by the National Institute for Drug Abuse R01 DA03773 and R37 DA019829. PV, NM, and SS also acknowledge support from NIAID and NIDA (R01AI147490). NM was additionally supported by the University of San Diego Center for AIDS Research (CFAR), a NIH funded program (P30 AI036214). AB also acknowledges support from NIDA (DP2DA049295). JS acknowledges support from NIDA (R01 DA033679). PV, MH and HF acknowledge support from the NIHR Health Protection Research Unit in Evaluation of interventions and Behavioural Science. This study used data from several studies: El Cuete (R37 DA019829), Mapa de Salud (R01 DA028692), Mujer Segua (R01 MH065849), Sexo Seguro (R01 AI036214 and R01 DA23877), Hombre Seguro (R01 MH065849) and Proyecto $\mathrm{H}$ (data collection through a Fogarty AIDS International Training in Research Program (AITRP) seed grant (PI Strathdee D43TW008633). The views expressed in this paper are solely those of the authors and not necessarily those of the University of Bristol, the National Health Service (NHS), the National Institute of Health Research (NIHR), the Department of Health and Social Care, or Public Health England (PHE).

Data Availability Study data is available upon request.

Code Availability Model code is available upon request.

\section{Declarations}

Conflicts of interest HF has received an honorarium from MSD. JS reports non-financial support from Gilead. MH has received unrestricted honoraria from Gilead and MSD in last 2 years. NM has received unrestricted research grants from Gilead and Merck. PV has received honoraria from Gilead and Abbvie unrelated to this research, and unrestricted research funding from Gilead unrelated to this work. All other authors have no disclosures.

Ethical Approval Not applicable because modelling analysis.

Consent to Participate Not applicable.

Consent for Publication Not applicable. 
Open Access This article is licensed under a Creative Commons Attribution 4.0 International License, which permits use, sharing, adaptation, distribution and reproduction in any medium or format, as long as you give appropriate credit to the original author(s) and the source, provide a link to the Creative Commons licence, and indicate if changes were made. The images or other third party material in this article are included in the article's Creative Commons licence, unless indicated otherwise in a credit line to the material. If material is not included in the article's Creative Commons licence and your intended use is not permitted by statutory regulation or exceeds the permitted use, you will need to obtain permission directly from the copyright holder. To view a copy of this licence, visit http://creativecommons.org/licenses/by/4.0/.

\section{References}

1. UNAIDS. Global HIV \& AIDS statistics - 2019 fact sheet. 2019;https://www.unaids.org/en/resources/fact-sheet.

2. Boily MC, Pickles M, Alary M, et al. What really is a concentrated HIV epidemic and what does it mean for West and Central Africa? Insights from mathematical modeling. J Acquir Immune Defic Syndr. 1999;2015(68 Suppl 2):S74-82.

3. Boily MC, Shubber Z. Modelling in concentrated epidemics: informing epidemic trajectories and assessing prevention approaches. Curr Opin HIV AIDS. 2014;9(2):134-49.

4. Mishra S, Boily MC, Schwartz S, et al. Data and methods to characterize the role of sex work and to inform sex work programs in generalized HIV epidemics: evidence to challenge assumptions. Ann Epidemiol. 2016;26(8):557-69.

5. Miller CL, Firestone M, Ramos R, et al. Injecting drug users' experiences of policing practices in two Mexican-US border cities: public health perspectives. Int J Drug Policy. 2008;19(4):324-31.

6. Strathdee SA, Philbin MM, Semple SJ, et al. Correlates of injection drug use among female sex workers in two Mexico-US border cities. Drug Alcohol Depend. 2008;92(1-3):132-40.

7. Syvertsen JL, Robertson AM, Abramovitz D, et al. Study protocol for the recruitment of female sex workers and their non-commercial partners into couple-based HIV research. BMC Public Health. 2012;12:136.

8. Mehta SR, Wertheim JO, Brouwer KC, et al. HIV transmission networks in the San Diego-Tijuana border region. EBioMedicine. 2015;2(10):1456-63.

9. Iniguez-Stevens E, Brouwer KC, Hogg RS, et al. Estimating the 2006 prevalence of HIV by gender and risk groups in Tijuana, Mexico. Gac Med Mex. 2009;145(3):189-95.

10. Bórquez A, Abramovitz D, Cepeda J, et al. Syringe sharing among people who inject drugs in Tijuana: before and after the Global Fund. Salud Mental. 2019;42(4):149-56.

11. UNAIDS. http://www.unaids.org/en/regionscountries/countries/ mexico. (accessed 11/03 2019). 2019.

12. Patrick R, Jain J, Harvey-Vera A, et al. Perceived barriers to preexposure prophylaxis use among HIV-negative men who have sex with men in Tijuana, Mexico: A latent class analysis. PLoS ONE. 2019;14(8):e0221558.

13. Silverman JG, Servin A, Goldenberg SM, et al. Sexual violence and HIV infection associated with adolescent vs adult entry into the sex trade in Mexico. JAMA. 2015;314(5):516-8.

14. Pitpitan EV, Goodman-Meza D, Burgos JL, et al. Prevalence and correlates of HIV among men who have sex with men in Tijuana, Mexico. J Int AIDS Soc. 2015;18:19304.

15. Robertson AM, Garfein RS, Wagner KD, et al. Evaluating the impact of Mexico's drug policy reforms on people who inject drugs in Tijuana, B.C., Mexico, and San Diego, CA, United
States: a binational mixed methods research agenda. Harm Reduct J. 2014;11:4.

16. Strathdee SA, Lozada R, Martinez G, et al. Social and structural factors associated with HIV infection among female sex workers who inject drugs in the Mexico-US border region. PLoS ONE. 2011;6(4):e19048.

17. Pitpitan EV, Chavarin CV, Semple SJ, et al. Hombre Seguro (Safe Men): a sexual risk reduction intervention for male clients of female sex workers. BMC Public Health. 2014;14:475.

18. Patterson TL, Goldenberg S, Gallardo M, et al. Correlates of HIV, sexually transmitted infections, and associated high-risk behaviors among male clients of female sex workers in Tijuana, Mexico. AIDS (London, England). 2009;23(13):1765-71.

19. Hollingsworth TD, Anderson RM, Fraser C. HIV-1 transmission, by stage of infection. J Infect Dis. 2008;198(5):687-93.

20. Morgan D, Mahe C, Mayanja B, Whitworth JA. Progression to symptomatic disease in people infected with HIV-1 in rural Uganda: prospective cohort study. BMJ (Clinical research ed). 2002;324(7331):193-6.

21. Lawn SD, Little F, Bekker LG, et al. Changing mortality risk associated with CD4 cell response to antiretroviral therapy in South Africa. AIDS (London, England). 2009;23(3):335-42.

22. Brinkhof MW, Boulle A, Weigel R, et al. Mortality of HIVinfected patients starting antiretroviral therapy in sub-Saharan Africa: comparison with HIV-unrelated mortality. PLoS Med. 2009;6(4):e1000066.

23. Mills EJ, Bakanda C, Birungi J, et al. Mortality by baseline CD4 cell count among HIV patients initiating antiretroviral therapy: evidence from a large cohort in Uganda. AIDS (London, England). 2011;25(6):851-5.

24. May M, Boulle A, Phiri S, et al. Prognosis of patients with HIV-1 infection starting antiretroviral therapy in sub-Saharan Africa: a collaborative analysis of scale-up programmes. Lancet (London, England). 2010;376(9739):449-57.

25. Althoff KN, Chandran A, Zhang J, et al. Life-expectancy disparities among adults with HIV in the United States and Canada: The impact of a reduction in drug- and alcohol-related deaths using the lives saved simulation model. Am J Epidemiol. 2019;188(12):2097-109.

26. Baggaley RF, White RG, Boily MC. HIV transmission risk through anal intercourse: systematic review, meta-analysis and implications for HIV prevention. Int J Epidemiol. 2010;39(4):1048-63.

27. Boily MC, Baggaley RF, Wang L, et al. Heterosexual risk of HIV-1 infection per sexual act: systematic review and meta-analysis of observational studies. Lancet Infect Dis. 2009;9(2):118-29.

28. Mukandavire C, Walker J, Schwartz S, et al. Estimating the contribution of key populations towards the spread of HIV in Dakar, Senegal. J Int AIDS Soc. 2018;21:e25126.

29. Strathdee SA, Magis-Rodriguez C, Mays VM, et al. The emerging HIV epidemic on the Mexico-US border: an international case study characterizing the role of epidemiology in surveillance and response. Ann Epidemiol. 2012;22(6):426-38.

30. Del Río C, Sepúlveda J. AIDS in Mexico: lessons learned and implications for developing countries. AIDS (London, England). 2002;16(11):1445-57.

31. Servin AE, Brouwer KC, Gordon L, et al. Vulnerability Factors and Pathways Leading to Underage Entry into Sex Work in two Mexican-US Border Cities. The journal of applied research on children : informing policy for children at risk. 2015;6(1).

32. Conners EE, West BS, Roth AM, et al. Quantitative, qualitative and geospatial methods to characterize HIV risk environments. PLoS ONE. 2016;11(5):e0155693.

33. Toni T, Welch D, Strelkowa N, et al. Approximate Bayesian computation scheme for parameter inference and model selection in dynamical systems. J R Soc Interface. 2009;6(31):187-202. 
34. Briggs A, Claxton K, Sculpher M. Decision Modelling for Health Economic Evaluation. Oxford: Oxford University Press; 2006.

35. Stone J, Fraser H, Lim AG, et al. Incarceration history and risk of HIV and hepatitis $C$ virus acquisition among people who inject drugs: a systematic review and meta-analysis. Lancet Infect Dis. 2018;18(12):1397-409.

36. Sordo L, Barrio G, Bravo MJ, et al. Mortality risk during and after opioid substitution treatment: systematic review and meta-analysis of cohort studies. BMJ (Clinical research ed). 2017;357:j1550.

37. Borquez A, Beletsky L, Nosyk B, et al. The effect of public healthoriented drug law reform on HIV incidence in people who inject drugs in Tijuana, Mexico: an epidemic modelling study. The Lancet Public health. 2018;3(9):e429-37.

38. Semple SJ, Pitpitan EV, Goodman-Meza D, et al. Correlates of condomless anal sex among men who have sex with men (MSM) in Tijuana, Mexico: The role of public sex venues. PLoS ONE. 2017;12(10):e0186814.

39. Strathdee SA, Abramovitz D, Lozada R, et al. Reductions in HIV/ STI incidence and sharing of injection equipment among female sex workers who inject drugs: results from a randomized controlled trial. PLoS ONE. 2013;8(6):e65812.

40. Burgos JL, Patterson TL, Graff-Zivin JS, et al. Cost-effectiveness of combined sexual and injection risk reduction interventions among female sex workers who inject drugs in two very distinct Mexican border cities. PLoS ONE. 2016;11(2):e0147719.

41. Werb D, Strathdee SA, Vera A, et al. Spatial patterns of arrests, police assault and addiction treatment center locations in Tijuana, Mexico. Addiction (Abingdon, England). 2016;111(7):1246-56.

42. Beletsky L, Lozada R, Gaines T, et al. Syringe confiscation as an HIV risk factor: The public health implications of arbitrary policing in Tijuana and Ciudad Juarez. Mexico Journal of Urban Health. 2013;90(2):284-98.

43. Smith LR, Patterson TL, Magis-Rodriguez C, et al. Engagement in the HIV Care Continuum among Key Populations in Tijuana. Mexico AIDS Behav. 2016;20(5):1017-25.

44. Servin AE, Muñoz FA, Zúñiga ML. Healthcare provider perspectives on barriers to HIV-care access and utilisation among Latinos living with HIV in the US-Mexico border. Cult Health Sex. 2014; 16(5):587-99.

45. Cepeda JA, Bórquez A, Magana C, et al. Modelling integrated antiretroviral treatment and harm reduction services on HIV and overdose among people who inject drugs in Tijuana, Mexico. JIAS. 2020;23(S1):e25493.

46. Hoornenborg E, Krakower DS, Prins M, Mayer KH. Pre-exposure prophylaxis for MSM and transgender persons in early adopting countries. 2017;31(16):2179-91.

47. aidsmap. PrEP prevents an estimated three-quarters of HIV infections in people at risk in large African study. https://wwwaidsmapcom/news/jul-2020/prep-prevents-estimated-three-quarters-hivinfections-people-risk-large-african-study. 2020.

48. Hanscom B, Janes HE, Guarino PD, et al. Brief report: Preventing HIV-1 infection in women using oral preexposure prophylaxis: A meta-analysis of current evidence. Journal of Acquired Immune Deficiency Syndromes (1999). 2016;73(5):606-8.

49. Baeten JM, Palanee-Phillips T, Brown ER, et al. Use of a vaginal ring containing dapivirine for HIV-1 prevention in women. N Engl J Med. 2016;375(22):2121-32.

50. Landovitz R. HPTN083 interim results: Pre-exposure prophylaxis (PrEP) containing long-acting injectable cabotegravir (CABLA) is safe and highly effective for cisgender men and transgender women who have sex with men (MSM,TGW). AIDS 2020 Virtual2020.

51. Jain JP, Strathdee SA, Patterson TL, et al. Perceived barriers to pre-exposure prophylaxis use and the role of syndemic factors among female sex workers in the Mexico-United States border region: a latent class analysis. AIDS Care. 2020;32(5):557-66.
52. Pines HA, Strathdee SA, Hendrix CW, et al. Oral and vaginal HIV pre-exposure prophylaxis product attribute preferences among female sex workers in the Mexico-US border region. Int J STD AIDS. 2019;30(1):45-55.

53. Wesson P, Reingold A, McFarland W. Theoretical and empirical comparisons of methods to estimate the size of hard-to-reach populations: A systematic review. AIDS Behav. 2017;21(7):2188-206.

54. Abdul-Quader AS, Baughman AL, Hladik W. Estimating the size of key populations: current status and future possibilities. Curr Opin HIV AIDS. 2014;9(2):107-14.

55. Brouwer KC, Strathdee SA, Magis-Rodriguez C, et al. Estimated numbers of men and women infected with HIV/AIDS in Tijuana, Mexico. Journal of urban health : bulletin of the New York Academy of Medicine. 2006;83(2):299-307.

56. Kerr CC, Stuart RM, Gray RT, et al. Optima: A Model for HIV epidemic analysis, program prioritization, and resource optimization. Journal of Acquired Immune Deficiency Syndromes (1999). 2015;69(3):365-76.

57. Kelly SL, Martin-Hughes R, Stuart RM, et al. The global Optima HIV allocative efficiency model: targeting resources in efforts to end AIDS. The lancet HIV. 2018;5(4):e190-8.

58. Melesse DY, Shafer LA, Emmanuel F, et al. Heterogeneity in geographical trends of HIV epidemics among key populations in Pakistan: a mathematical modeling study of survey data. J Glob Health. 2018;8(1):010412.

59. Rao AS, Thomas K, Sudhakar K, Maini PK. HIV/AIDS epidemic in India and predicting the impact of the national response: mathematical modeling and analysis. Mathematical Biosciences and Engineering : MBE. 2009;6(4):779-813.

60. Maheu-Giroux M, Baral S, Vesga JF, et al. Anal intercourse among female sex workers in cote d'Ivoire: Prevalence, determinants, and model-based estimates of the population-level impact on HIV Transmission. Am J Epidemiol. 2018;187(2):287-97.

61. Mitchell KM, Foss AM, Prudden HJ, et al. Who mixes with whom among men who have sex with men? Implications for modelling the HIV epidemic in southern India. J Theor Biol. 2014;355:140-50.

62. Guy RJ, Wand H, Wilson DP, et al. Using population attributable risk to choose HIV prevention strategies in men who have sex with men. BMC Public Health. 2011;11:247.

63. Borquez A, Guanira JV, Revill P, et al. The impact and cost-effectiveness of combined HIV prevention scenarios among transgender women sex-workers in Lima, Peru: a mathematical modelling study. The Lancet Public health. 2019;4(3):e127-36.

64. Maheu-Giroux M, Vesga JF, Diabate S, et al. Changing Dynamics of HIV Transmission in Cote d'Ivoire: Modeling Who Acquired and Transmitted Infections and Estimating the Impact of Past HIV Interventions (1976-2015). Journal of acquired immune deficiency syndromes (1999). 2017;75(5):517-27.

65. Anderson SJ, Cherutich P, Kilonzo N, et al. Maximising the effect of combination HIV prevention through prioritisation of the people and places in greatest need: a modelling study. Lancet (London, England). 2014;384(9939):249-56.

66. Pickles M, Boily MC, Vickerman P, et al. Assessment of the population-level effectiveness of the Avahan HIV-prevention programme in South India: a preplanned, causal-pathway-based modelling analysis. Lancet Glob Health. 2013;1(5):e289-99.

67. Low A, Nagot N, Konate I, et al. Potential impact of existing interventions and of antiretroviral use in female sex workers on transmission of HIV in Burkina Faso: a modeling study. J Acquir Immune Defic Syndr. 1999;2015(68 Suppl 2):S180-8.

68. Steen R, Hontelez JA, Veraart A, et al. Looking upstream to prevent HIV transmission: can interventions with sex workers alter the course of HIV epidemics in Africa as they did in Asia? AIDS (London, England). 2014;28(6):891-9. 
69. Burgos JL, Cepeda JA, Kahn JG, et al. Cost of provision of opioid substitution therapy provision in Tijuana, Mexico. Harm Reduct J. 2018;15(1):28.
Publisher's Note Springer Nature remains neutral with regard to jurisdictional claims in published maps and institutional affiliations. 